\title{
The "burden of normality": concepts of adjustment after surgery for seizures
}

\author{
S Wilson, P Bladin, M Saling
}

\begin{abstract}
Objectives-To conceptualise the process of adjustment provoked by the sudden alleviation of chronic epilepsy by temporal lobectomy. On being rendered seizure free, the process of adjustment primarily depends on the patient's capacity to discard roles associated with chronic epilepsy and to learn to become well. This can involve a reconceptualisation of the patient's identity from chronically ill to "cured", and can give rise to a constellation of psychological, affective, behavioural, and sociological features characterised as the "burden of normality".

Methods-This is a theoretical inquiry that documents the clinical phenomenology of the burden of normality by classifying its key psychological and psychosocial features. The model of adjustment is presented in the context of previous outcome research on surgery for seizures, providing a conceptual link between practice based rehabilitation measures of outcome and multidimensional constructs, such as health related quality of life.

Results-The model represents a process oriented, theoretical framework for comprehensively measuring outcome after life changing medical interventions. It has implications for clinical practice, including the identification of preoperative predictors of outcome and informing appropriate management and rehabilitation of patients.

Conclusion-This model of outcome after temporal lobectomy may ultimately be applicable to the treatment of other chronic conditions.

(F Neurol Neurosurg Psychiatry 2001;70:649-656)
\end{abstract}

Keywords: postperative adjustment: psychosocial outcome; seizure surgery; health related quality of life

Advances in medicine are leading to the alleviation of previously untreatable chronic conditions. Attention is now turning to the psychosocial ramifications of what are often invasive and expensive treatments. Traditionally, psychosocial researchers have been preoccupied with the process of adjustment in patients acquiring a disability. There have been few attempts, however, to conceptualise the process of adaptation which is provoked by sudden alleviation of chronic illness.

This paper presents the surgical treatment of chronic epilepsy as a paradigm on which to model this general process of adjustment. In doing so, it challenges current methods of outcome assessment in the field of seizure surgery. The model provides a broad framework to link the approaches of previous research on the outcome of seizure surgery, and to account for some of the current variability in outcome data. Discussion of the model is preceded by a brief conceptual overview of research on the outcome of seizure surgery leading up to current approaches, to place the model in its broader context.

\section{Conceptual overview}

DEFINING OUTCOME

The application of surgery to the treatment of epilepsy in one form or another is well over a century old. ${ }^{12}$ Even so, it was not until the delineation of "psychomotor epilepsy" with the involvement of the temporal lobe that ablative operation was conceived as a cure for a specific form of seizure..$^{3-5}$ The earliest reports of the use of anterior temporal lobectomy measured surgical efficacy in terms of preoperative and postoperative seizure frequency. ${ }^{3-5}$ Soon after, the psychological functioning of the patient was also considered. ${ }^{67}$ This was mainly due to the referral of surgical candidates from psychiatric sources, and partly because of the then current opinion associating temporal lobe epilepsy with psychological problems.

Early postsurgical assessment of patients included, therefore, measures taken to highlight psychological improvement as well as the diminution of seizure frequency. The data generally suggested that psychiatric improvement followed seizure improvement despite a time lag, often of 12 to 24 months, between the two. ${ }^{8-11}$ During this lag transient worsening of mood or behaviour could occur, and this was attributed to a process of psychological adjustment. It was thought, however, that long term psychosocial benefits could be realised with supportive psychotherapy and follow up. ${ }^{11}$

The potential psychosocial benefits of seizure surgery were considered in relation to the patient's preoperative psychosocial state. This included possible disruptive effects of intractable seizures on the patient's physical, emotional, and social development. It also included negative family reactions to seizures, such as overprotective attitudes or enmeshed family dynamics. ${ }^{12}$ Early researchers argued that "neurotic patterns of adjustment" often accompany epilepsy, with seizures playing only one part in the patient's total disability. They noted that control of seizures through surgery does not automatically abolish these learnt patterns of behaviour nor alter previously established family and social relationships. ${ }^{10-14}$ Thus, after surgery there may be a period of re-education and adjustment, as the patient learns to live without epilepsy. 
"When seizures are successfully controlled the patient must continue interrupted development - form new roles, progress to new adaptations, develop a healthy identity, and give up dependency, passivity, and other immature interpersonal styles. To the degree the patient fails in this difficult task residual psychological and behavioural symptoms will remain." 13

Ferguson and Rayport examined the psychological benefits of seizures, and the response of five patients to the loss of these benefits after "successful" surgery for seizures. ${ }^{14}$ In particular, they argued that chronic epilepsy may allow significant benefits in both emotional and social adjustment. Emotionally, the illness may excuse behaviour which would normally provoke feelings of guilt. Socially, the illness may protect the patient from day to day demands, as well as allow recognition, despite inadequacy of performance. In their words "the illness may serve both as a weapon and as a shield." ${ }^{14}$ On being rendered seizure free the patient is effectively disarmed, no longer receiving the consideration extended to the chronically ill. New intrapersonal and interpersonal demands may be required of the patient, for which he or she has limited experience and life skills. Thus, the return of seizures due to failed surgery may represent a welcome return to the previous situation.

Ferguson and Rayport compared the postoperative recovery of patients undergoing seizure surgery with the recovery of patients undergoing congenital cataract surgery, as described by von Senden. ${ }^{15}$ In the second case, patients are exposed to "a flood of new sensory impressions" for which they lack the appropriate visuoperceptual learning and development. In effect, these patients are "burdened with normality" and thrust into an "acute maturational phase". The comparison with anterior temporal lobectomy is perhaps not strictly accurate, as we are dealing with neuronal and perceptual reorganisation in one case, and psychosocial reorganisation in the other. None the less, Ferguson and Rayport made a cogent point when they quoted the words of Wishengrad: "perhaps you cannot take years of deformity and cut it off with just a knife."16

Many of the modern lifestyle changing operations (for instance, renal, cardiac, and pain surgery) involve considerable postoperative psychosocial reorganisation, ${ }^{17}{ }^{18}$ and it has been shown by Bladin that this applies equally to temporal lobectomy. ${ }^{19-21}$ Despite the differing cause and complexity of these conditions, patient enthusiasm over newfound health and abilities can give way to a period of crisis, and in some cases, poor long term adjustment may result without appropriate postoperative rehabilitation and support. The potential range of outcomes varies from a patient view of subjective improvement without objective change, to objective improvement accompanied by subjective worsening. According to Ferguson and Rayport, this variability of outcome can only be reconciled "when account is taken of the relation of the illness to the patient's psychic needs."14
DOMAINS OF PSYCHOSOCIAL OUTCOME

Psychosocial outcome research has traditionally measured the impact of seizure surgery on patient functioning across a range of domains, including personal independence, family and social relationships, vocational and recreational functioning, and sexual adjustment. Measurement of patient functioning in these domains has involved the use of interviewer rating scales $^{12} 1^{1322-25}$ or semistructured interviews ${ }^{20}$ designed to provide a comprehensive view of the patients' psychosocial status postsurgery. In general, this research has shown that psychosocial improvement is related to seizure relief, although seizure relief itself is not a sufficient condition for good postoperative adjustment. There can be considerable variation in the amount of improvement in specific psychosocial domains pertaining to one patient and also between patients in different series.

On the basis of a recent review of this literature Fraser and Thorbecke ${ }^{26}$ concluded that postoperative improvement in interpersonal relationships occurs in about two thirds of patients after seizure surgery. By contrast, vocational functioning is more resistant to change, and improvements are mainly seen in patients who are seizure free, or nearly seizure free. About $50 \%$ of patients reported improved sexual functioning, again commonly linked to seizure relief. Transient depression and anxiety occurred in up to $25 \%$ of cases, with suicide posing a serious risk in a few patients. Postoperative psychosis was noted to develop in fewer than $10 \%$ of patients. This review clearly shows that a significant proportion of patients (albeit a minority) have postoperative psychosocial difficulties despite seizure relief.

It has been concluded that postoperative care should be provided routinely to all patients, ${ }^{2026}$ and is predictable from the degree of maladjustment before surgery. ${ }^{122}$ Specific rehabilitation strategies have been recommended to improve patient functioning in problematic domains. ${ }^{26-28}$ It has also been suggested that rehabilitation be started before surgery. ${ }^{26}{ }^{29}$ This allows preoperative expectations of the patient and family to be assessed, ensuring mutually shared outcome goals between the patient and the surgical team. Taylor et al recently published a method of formally coding preoperative expectations with respect to postoperative outcome. ${ }^{29}$ They argued that a failure to document presurgical expectations produces a scientifically weak situation. It allows claims of success which lack a preoperative baseline and which cannot be predicted.

Finally, the deleterious impact of operative failure on psychosocial outcome has been emphasised: "it appeared to ensure persistence of any problems that existed preoperatively and significantly worsened them in several patients." ${ }^{20}$ Deterioration was found in vocational functioning, as well as family and social relationships. In all cases, there was "unanimity of opinion regarding the magnitude of surgical failure and non-fulfilment of expectations." ${ }^{20}$ The fallacy of speculative seizure surgery on the presumption that "the patient could not be worse off" is thereby highlighted. 
The approach of psychosocial outcome research has been criticised on methodological and psychometric grounds. For example, Vickrey et al argued that most studies have been constrained by small sample sizes, the use of retrospective designs, and a failure to account for the baseline functioning of the patient. ${ }^{30}$ More importantly, however, it has also been suggested that this research was unable to evaluate psychosocial outcome reliably. ${ }^{30} 31$

THE HEALTH RELATED QUALITY OF LIFE (HRQOL) APPROACH

"Postoperative freedom from seizures should improve psychosocial status: however, clear evidence for this reasonable assumption is lacking in part because to date few objective tools have been available to assess outcome." 31

MEASUREMENT

The concept of quantitatively measuring the effects of a disease on a patient's quality of life was introduced in the late 1940s by Karnovsky, in the context of treating terminally ill patients. ${ }^{32}$ Conceptually, it affirms measurable improvement in the patient's physical, mental, and social wellbeing as the gold standard of outcome. In 1990, the National Institutes of Health convened a consensus conference on surgery for epilepsy. This led to the recommendation of the development of a HRQOL questionnaire to measure the efficacy of seizure surgery in chronic epilepsy. ${ }^{30} 3133$

In response to this recommendation, Vickrey et al developed the epilepsy surgery inventory-55 (ESI-55), the principal instrument used to measure HRQOL in patients after surgery for epilepsy. ${ }^{3133} 34$ It samples the patient's perception of daily functioning and feelings of wellbeing across four health dimensions, including general, physical, mental, and social health. When administered to patients postoperatively, it showed significant improvement on about half of the subscales, in comparison with a nonsurgical group. There was no difference, however, in overall quality of life for these two groups. ${ }^{35}$ Scores have been shown to correlate positively with degree of seizure control, suggesting that objective seizure relief is an antecedent of greater patient wellbeing, as measured by the ESI- $55 .^{33}{ }^{34}$ A recent study by Gilliam et al, however, did not replicate this effect, showing that mood status, employment, driving, and anticonvulsant cessation were more important predictors of HRQOL. ${ }^{36}$ The authors indicated that this pattern of prediction was not explained by multicollinearity.

As in the work of Vickrey et al, HRQOL questionnaires have been used primarily to obtain a cross sectional "snapshot" of postoperative outcome. ${ }^{33}{ }^{35}$ In this context, the ESI-55 has been shown to provide a reliable and valid assessment of HRQOL which is sensitive to differences in postoperative seizure status. ${ }^{33}$ Wiebe et al noted, however, that few data exist on the ability of HRQOL instruments to detect clinically important change over time:
"Evidence of scale reliability and aspects of cross sectional validity (for example, content, construct, and convergent validity) do not guarantee responsiveness, which may be viewed as an aspect of longitudinal validity or as a separate measurement dimension. Demonstrated responsiveness is particularly important in observational (non-randomised controlled) studies or in studies whose only test results available are those obtained after the intervention." ${ }^{37}$

Wiebe et al compared the responsiveness of the ESI-55 to a general measure of psychological adjustment and distress, and an epilepsy specific psychosocial instrument, in a prospective cohort of surgically and medically treated patients with temporal lobe epilepsy. ${ }^{37}$ Contrary to their expectations, the general measure of adjustment showed the highest overall responsiveness ranking compared with the epilepsy specific tools. Furthermore, subscales of the ESI-55 containing epilepsy specific items were found to be less responsive than subscales stemming from the generic component of the ESI-55, with the exception of the health perceptions subscale.

In the same group of patients, McLachlan et al examined the responsiveness of the ESI-55 both before and 6,12 , and 24 months after treatment. $^{38}$ They showed that changes on the ESI-55 were only evident for one of the 11 subscales at 6 months postsurgery, and two of the subscales at 12 months, compared with six of the 11 subscales at the 24 month postoperative mark. McLachlan et al suggested that a similar lack of change has been shown for the early impact (under 24 months) of treatment of ovarian cancer on patients' self perceived quality of life. ${ }^{38}$ Hence, cross sectional evaluation of HRQOL 2 or more years after treatment may provide a better estimate of outcome than evaluation before this time.

When the ESI-55 is administered 2 years after temporal lobectomy, change in HRQOL is predicted by preoperative HRQOL scores. ${ }^{39}$ This is particularly true for patients with low or medium preoperative scores, who show larger changes in postoperative HRQOL than patients with higher baseline scores. Unexpectedly, however, this study found that postoperative seizure outcome failed to predict change in postoperative HRQOL across a range of subscales of the ESI-55 once the effects of preoperative HRQOL had been controlled for. Rose et al concluded that, similar to previous studies in nonneurological conditions, longitudinal quality of life research highlights the importance of obtaining baseline HRQOL scores. ${ }^{39}$

According to O'Donoghue et al, sensitivity to change is compromised when disparate psychosocial consequences of disease are conceptualised within a single measurement framework, because: "The time course over which symptoms, as opposed to social functioning, are likely to improve are very different. The causal mechanisms and, more importantly, the appropriate interventions at the various levels of disease consequence are quite different." ${ }^{\prime 40}$ 
This has led to the suggestion that HRQOL provides a global patient view of outcome that canvasses the major psychosocial aspects of disease. ${ }^{26344041}$ In other words, it reflects a general state of wellbeing at a given point in time, rather than a process of adjustment which depends on change in multiple domains.

THEORETICAL ALTERNATIVE

In a seminal work on the theoretical underpinnings of subjective wellbeing, Headey and Wearing proposed that the desire to experience high levels of wellbeing represents a fundamental human goal. $^{42}$ To achieve this, people construct a set of current life perceptions that is psychologically consistent with their expectations, thereby bolstering feelings of subjective wellbeing:

"People arrive at an equilibrium state in which their present life is viewed as being almost as satisfying as the life they expect, the best life they could aspire to, the life they think they deserve, and the best previous period of their life." ${ }^{42}$

This equilibrium state accounts for the finding that differences in subjective ratings of wellbeing are relatively small, despite large objective differences in the socioeconomic status of persons and groups within society. ${ }^{42}{ }^{43}$ People living in the most disadvantaged objective conditions still give favourable ratings of subjective wellbeing. Likewise, normative studies of people with disabilities have shown ratings of subjective wellbeing as high or higher than nondisadvantaged people. ${ }^{42}{ }^{44}$ According to Cummins, this finding runs counter to a widely held assumption in HRQOL that disease and injury result in lower levels of quality life than that expected in the normal population. ${ }^{43}{ }^{44}$

Cummins has proposed that subjective wellbeing is actively managed by a complex system of cognitive biases that bolster a person's sense of wellbeing. ${ }^{43}$ Furthermore, this system is under homeostatic control, analogous to the physiological processes of the body that maintain blood pressure. In effect, subjective wellbeing is "an essential and basic component of human existence . . no less important than the traditional requirements for species survival." 43 Homeostatic control of subjective wellbeing accounts for its remarkably restricted range of ratings, evident across western and non-western countries. It also accounts for the lack of systematic influence of objective conditions on subjective wellbeing, except in extreme conditions. ${ }^{42} 43$

According to Headey and Wearing, change in the equilibrium state of wellbeing is only likely to occur in the context of unusually favourable or adverse life events. ${ }^{42}$ The former serve to enhance subjective wellbeing, whereas the latter increase psychological distress. This is because unusual life events can produce a change in the gap between a person's assessment of his or her current life and expectations for the future. In the short term (2 years or less), favourable events will reduce the gap whereas adverse events will increase it. ${ }^{42}$ Seizure surgery may constitute an unusually favourable or adverse life event. In either case, a reassessment of the gap between the patient's expectations of surgery and his or her postoperative life may be provoked. This, in turn, may directly affect postoperative levels of wellbeing or distress. The key feature of this conceptualisation is that it highlights the importance of the construct of expectation.

Headey and Wearing have suggested that a problem with quality of life questionnaires is their limited assessment of psychological distress. $^{42}$ Factor analytical studies of positive affect, life satisfaction, and happiness (subjective wellbeing), and anxiety and depression (psychological distress) have shown that wellbeing and distress are distinct dimensions, and not opposite ends of the same continuum. ${ }^{45-48}$ This is particularly true for anxiety states, during which persons can perceive life as both quite satisfying and quite stressful. Despite generally high levels of subjective wellbeing in most people, symptoms of psychological distress are also relatively widespread. ${ }^{42}$ Health related quality of life questionnaires have tended to document the extent of change in a patient's wellbeing postsurgery, while neglecting the degree of distress associated with postoperative adjustment difficulties.

THE “BURDEN OF NORMALITY": A MODEL OF PSYCHOSOCIAL ADJUSTMENT

It is clear that the research literature is somewhat divided in its approach to characterising and measuring the psychological and psychosocial issues of outcome of seizure surgery. The application of an HRQOL questionnaire to outcome measurement has considered many of the methodological concerns within the literature, but it does not seem to have captured the underlying psychological and psychosocial issues of adjustment discussed by earlier researchers. Inclusion of the fundamental elements of both approaches is required to develop a comprehensive model of outcome.

The model presented in this paper is a conceptualisation of the process of psychological and psychosocial adjustment surrounding seizure surgery. It emerges from careful clinical findings and previous research conducted within the context of our seizure surgery follow up and rehabilitation programme. ${ }^{19-2127} 49-51$ Our approach has been guided by the principle that careful clinical findings need to precede the development of psychometrically validated and reliable instruments, as without such findings psychometric instruments are likely to lack clinical and ecological validity.

The basic premise of our model is that life changing medical interventions challenge a patient's level of adjustment in a way that can serve to enhance or to undermine psychological and psychosocial function. In the case of seizure surgery, adjustment primarily depends on the patient's capacity to discard roles associated with chronic epilepsy and to learn to become well. This process is complex and far reaching, involving a reconceptualisation of the patient's identity from chronically ill to "cured". The clinical manifestations of this process reliably co-occur, and we have characterised them as 


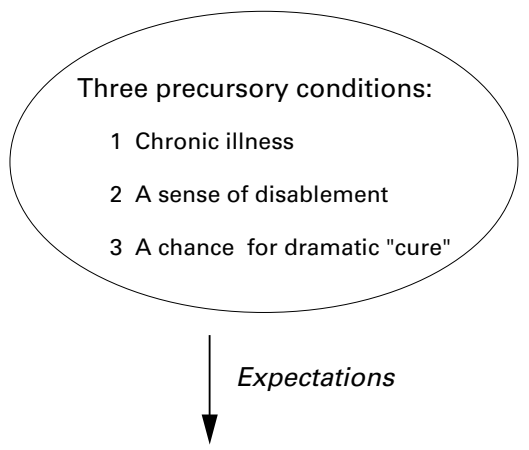

The syndrome:

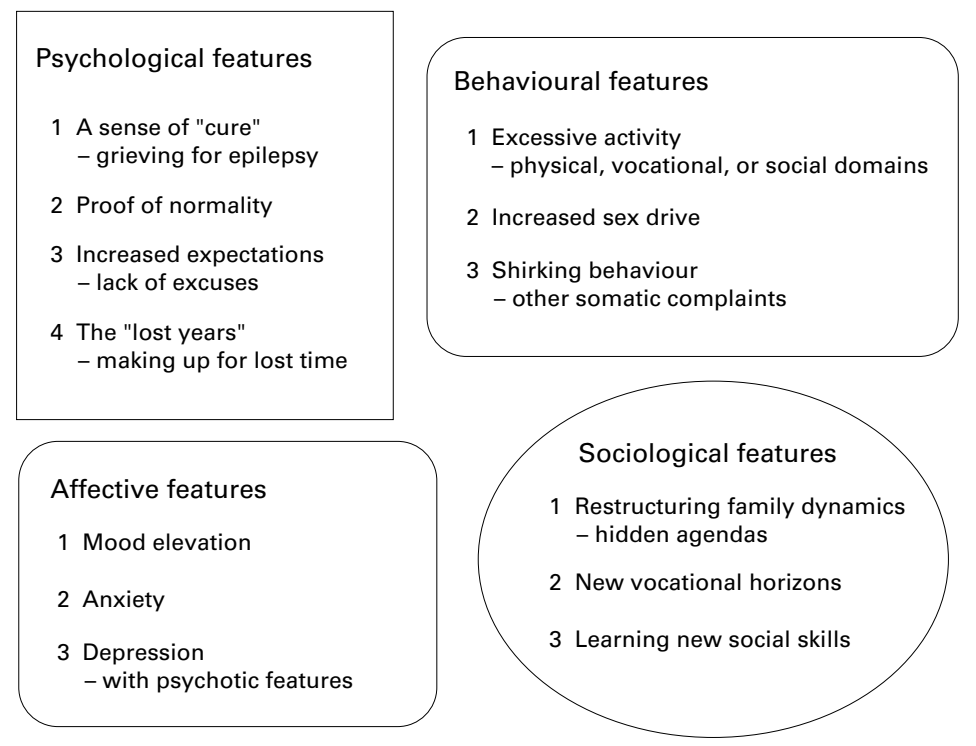

Figure 1 The "burden of normality".

the "burden of normality". This is a syndrome which comprises psychological, affective, behavioural, and sociological features.

PRECURSORY FEATURES

The burden of normality seems to occur within the context of three precursory conditions: (1) chronic illness, (2) a sense of disablement, and (3) a chance for dramatic "cure" (fig 1). It has been well recognised that patients with chronic illness "face permanent changes in lifestyle, threats to dignity and self esteem, disruption of normal life transitions, and decreasing resources. ${ }^{~}{ }^{52}$ In the case of early onset chronic epilepsy, patients must deal with the extent to which they see themselves as "epileptic". As noted by Taylor, to be an epileptic patient is, in one way, to be reconciled to an aspect of reality, but in another way, it involves incorporating something alien into the personality ${ }^{53}$ This may be accompanied by a sense of stigma, lowered self worth, or a sense of loss of entitlements imposed by the restrictions of epilepsy. ${ }^{53-55}$

Research by Tedman et al has previously shown that the epilepsy patient constructs a view of self that is different from those without epilepsy. ${ }^{56}$ This view is associated with core beliefs that reinforce the negative experience of having epilepsy, and in turn, affect coping skills. Examples of core beliefs include: "I would be a different person if I had never had epilepsy; I am different/inferior to others because of my epilepsy; I need to prove myself as better to be accepted as an equal; I am less confident than I would be if I didn't have epilepsy; I have not fulfilled my potential or role in life." 55

In all likelihood, core beliefs of this sort fuel the psychological and psychosocial features of the burden of normality. The chance of surgical "cure" often symbolises a gateway to a new life for the patient. This new life represents the life that should have been, were it not for epilepsy. In effect, the basis of the adjustment process is formed before surgery. It arises from the chronicity of epilepsy and the cascading psychosocial disablement it often provokes, coupled with high expectations of postoperative life. These expectations can be unrealistic, with patients expecting surgery to solve most, if not all, of their problems. ${ }^{13} 14997$ When preoperative expectations are not realised, postoperative levels of psychological distress may increase. ${ }^{20} 49$

The postoperative phase is fraught with potential difficulties as the patient is faced with life without chronic epilepsy. Disrupting the balance of living with the restrictions of longstanding disability and the demands of everyday life can give rise to a range of symptoms. ${ }^{13} 1820272851$ Alternatively, as noted by Taylor "being sick is one manner of being. That may not change by removing an epilepsy focus." ${ }^{53}$ Psychosocial consequences of chronic illness may persist as independent sources of distress after the apparent origin of the sickness has been relieved. ${ }^{1353}$

\section{PSYCHOLOGICAL FEATURES}

Clinically, we have found that psychological features of the burden of normality are often the first to appear postoperatively. Patients may experience a feeling of transformation: "like a new person", "reborn", or "full of confidence", associated with a sense of being cured (fig 1). Such features may appear dramatically and soon after the operation for some patients. Others have a more gradual sense of cure in which the contingent experience of transformation is less obvious. There may also be a period of grieving for the loss of epilepsy, akin to the loss of "an old friend". ${ }^{18}$ Chronic illness can be "a stimulus to bravery, giving the patient a justified sense of effort and achievement." ${ }^{18}$ Successful treatment of the illness can effectively remove this source of self esteem and social recognition. In essence, the psychological symptoms reflect the significance of the epilepsy to the patient's identity, and the underlying process of change in the patient's self image from chronically sick to well. Importantly, the underlying process of adjustment is not exclusively manifested at a psychological level, but may surface clinically in behavioural, affective, or social change.

A major complication of the patient's sense of cure can be non-compliance with the postoperative anticonvulsant regimen. Seizures arising from rapid anticonvulsant withdrawal may follow, and can have deleterious psychological and psychosocial consequences for the patient. These include significant questioning of the efficacy of surgery and the accompanying 
sense of cure; increased anxiety and depression; and reduced vocational, family, and social functioning.

Other cognitive beliefs that may stem from a change in self identity from chronically sick to well include a need for patients to prove themselves as "normal", both to themselves and their family and friends. This need is symbolic of an unburdening of the epilepsy, its associated stigma and restrictions, and on occasions, the notion that brain surgery is indicative of "brain damage". It is typically accompanied by an increase in the expectations that patients place on themselves, or the perceived expectations of their family and friends, which may directly relate to preoperative aspirations. This can generate a considerable amount of postoperative anxiety, as the patient no longer has the "excuse" of chronic epilepsy for personal, vocational, or social shortcomings.

Finally, on experiencing a life free from seizures, patients may report a sense of grief or outrage for the opportunities and years lost as a result of the limitations imposed by their epilepsy. This may engender a need to make up for lost time in the postoperative phase, including a sense of urgency or impatience for goals not yet achieved.

BEHAVIOURAL FEATURES

The psychological features of the burden of normality are often accompanied by observable changes in patient behaviour (fig 1). Excessive activity is commonly reported in physical exercise or, in some cases, physical stunts (such as sky diving), in work or domestic duties, or socialising. The last can include overindulgence in alcohol or drugs, sleep deprivation, and cessation of anticonvulsant drugs, as the patient celebrates a newfound freedom from seizures.

Patients also commonly report a change in their sex drive, which is typically increased, ${ }^{26}$ and associated with a heightened sense of awareness of their own sexuality and the sexuality of others. For most patients this is regarded as a positive side effect of surgery. In some cases, however, it may cause frustration within a previously well established sexual relationship, leading the patient to consider new potential partners. For single patients, it can produce an increased willingness to find a partner, and inexperienced patients may encounter unsafe situations for which they are unprepared. The basis of this change is not well understood. It may be psychological, arising from an improvement in the patient's self image, but there may be a neurobiological component, such as altered limbic system function..$^{59}$ Further research is required to consider this issue.

By contrast with the excessive behaviour of some patients, others struggle with the new demands of postoperative life, and engage in a range of shirking or avoidant behaviours. These may include resisting any attempts to change their psychosocial circumstances and an unwillingness to think that they are well, despite optimal seizure outcome. These patients seem to block the impetus towards personal growth and fail to discard sick roles. Other somatic complaints - such as headache, general fatigue, or pain-can develop as a replacement of seizures and become the focus of the patient's attention. Patients who experience ongoing auras in the postoperative phase may focus on these as evidence of their persisting illness, and in this way undermine the process of change. This phenomenon can be usefully conceptualised within the framework of learned helplessness. ${ }^{60}$ Further research is required to examine key factors which influence the degree of learned helplessness evidenced by patients with epilepsy, both presurgery and postsurgery.

\section{AFFECTIVE FEATURES}

Affective features of the burden of normality include mood elevation, anxiety, and depression (fig 1). These mood states may fluctuate from one to another or one state may predominate, usually soon after surgery. ${ }^{61}{ }^{62}$ Mood elevation is typically associated with the joy of cure and making it through surgery relatively unscathed, with symptoms akin to hypomania in some patients. ${ }^{22}$ Patients typically report "feeling on cloud nine" or "on top of the world", and describe a new appreciation and zest for life. This is often accompanied by behavioural excess as described above.

Anxiety and depressive symptoms tend to co-occur and are often somatic in nature. At a clinical level the somatic symptoms of panic disorder are occasionally difficult to differentiate from the symptoms of auras. Depressive features may involve a preoccupation with physical or cognitive complaints, including a bitter memory complaint, ${ }^{6364}$ undue concern about the surgical wound, the robustness of the bone flap, or the functioning of the brain itself. In a very small percentage of cases there may be more fully developed delusions, such as the belief that strangers know the patient has had brain surgery despite the absence of external markers of a craniotomy. Suicidal ideation may be reported, often with associated suicide plans or attempts.

Similar to postoperative changes in sexual function the underlying cause of postoperative mood disturbance is still debated, ${ }^{61}{ }^{62}$ with the role of psychological and neurobiological factors potentially varying across patients. The occurrence of mood disturbance as a postoperative complication, however, is now clearly recognised. ${ }^{65}$ In a recent study of 100 patients with an anterior temporal lobectomy (ATL) our group found that psychiatric diagnoses of anxiety, depression, or postictal psychosis were the most frequent reasons for patient readmission post-ATL. ${ }^{27}$

\section{SOCIOLOGICAL FEATURES}

Postoperative changes in the patient associated with the burden of normality may challenge the dynamics of the family unit (fig 1). Over time families develop mechanisms and structures to support a chronically ill member, ${ }^{14}{ }^{53}$ which may require radical refashioning at all levels within the family during the postoperative phase. $^{2066}$

The sudden change in the status of the patient from chronically ill to well often 
challenges the role of the primary carer, who may resist attempts of the patient to increase independence and continue to show established patterns of overconcern. This can result in considerable conflict, often described by carers as a difficulty "letting go" and accepting the patient's view of surgical "cure". Alternatively, increased aggression and hostility towards family and friends can be reported, as the patient attempts to exert greater levels of control and independence within the social milieu. In either case the conflict can lead to dissolution of relationships. When partners are involved "marriage initiated under one set of ground rules often fails to survive when those rules are suddenly and radically altered."20

Clinically, we have found that some patients proceed to surgery with a hidden agenda, which may involve becoming free of an overbearing partner once they are seizure free. Alternatively, family members may be looking for a solution to their responsibility of care as the patient ages and the question of long term support is raised. Sibling resentment may also emerge postoperatively, particularly if the "now cured" patient still maintains the sick role. ${ }^{20}$ Hidden agendas can give rise to unexpected postoperative complications, such as divorce and family breakdown, or the withdrawal of important preoperative support. ${ }^{20} 22$

Beyond the family setting, patients are often keen to consider new vocational and social horizons, particularly if their epilepsy has significantly interfered with their functioning in these domains. This can include a desire to resume educational or vocational activities that were initially disrupted by seizures, or to acquire new vocational skills. Preoperative vocational aspirations can cause postoperative disappointment, anxiety, or frustration if the patient fails to make vocational gains. Likewise, in the social domain immature personality styles and limited social skills may prevent social gains, or cause difficulties for patients and their families. Exposure to new situations and a lack of awareness of social constraints can result in inappropriate social behaviours.

\section{Summary}

The psychological, behavioural, affective, and sociological features of the burden of normality seem interrelated, arising as clinical manifestations of an underlying process of adjustment. The combination of features expressed by a given patient may vary as a function of his or her personal and medical history, and preoperative psychosocial context. The degree to which they are expressed may partly reflect preoperative levels of adjustment, as well as the extent of change in the patient's self perception from chronically sick to well. This, in turn, may disclose the degree to which epilepsy has been incorporated into the patient's identity. Our model suggests that for successful surgical candidates, the primary goal involves learning to live without seizures and discarding roles associated with chronic epilepsy. This adjustment process seems necessary for many patients to maximise both successful seizure and psychosocial outcome.
Implications of the model of adjustment Other researchers have recognised the importance of psychosocial adjustment in comprehensively measuring surgical outcome. ${ }^{10111314202849-51536067}$ Despite this, there have been no previous attempts to formally characterise the nature of this adjustment process. This paper presents our understanding of the process, as based on our clinical findings and previous research with patients who have undergone seizure surgery. ${ }^{19-21} 27$ 49-51 Understanding the process of adjustment provoked by seizure surgery is crucial in identifying preoperative predictors of outcome, especially in patients likely to have difficulties in the postoperative phase. An accurate description of this process is the first step in a theory driven approach to predictive outcome research. Although the model has been developed within the context of a seizure surgery programme, it is potentially applicable to the effective treatment of other chronic conditions.

The model of adjustment provides a broad conceptual framework to link the differing approaches and findings of previous research on outcome of seizure surgery. It is built on the findings of early researchers who recognised the psychological and psychosocial significance of chronic epilepsy and the potential intrapsychic difficulties that can be precipitated by its relief. It incorporates preoperative expectations and postoperative changes across a range of psychosocial domains, as evidenced by features of the burden of normality. It also recognises HRQOL as a global "snapshot" of patient wellbeing after seizure surgery. The process of adjustment surrounding surgery may impact on a patient's equilibrium state of wellbeing. Consideration of the patient's clinical state within the context of the adjustment process may provide a useful indicator of the most appropriate stage at which to administer HRQOL measures.

The aim of this paper was to develop a theoretical framework for psychosocial management in epilepsy programmes. What we are suggesting is something of a paradigm shift in the approach to measurement and management of psychosocial outcome. This approach is based on the fundamental notion that the relation between seizure outcome and psychosocial outcome is not a simple linear pattern, where seizure relief automatically leads to improvement at the psychosocial level. Rather, our model suggests that seizure surgery can set in train a complex cascade of events that represent the process of postoperative adjustment. Our work has set out to provide a naturalistic description of this process as it manifests psychosocially.

The model itself is not prescriptive of measurement or management techniques, other than to suggest that psychosocial adjustment issues are optimally handled within a face to face and longitudinal preoperative and postoperative context. The key issue is the way that the patient and his or her family are understood relative to chronic epilepsy rather than the application of any specific instrument or therapeutic strategy. In this way the model should ideally serve to stimulate the development of psychosocial 
programmes that are appropriate to the needs and conditions of local communities.

This research was presented in part at the 23rd International Epilepsy Congress in Prague, September 1999. It forms part of a research programme that was awarded the inaugural SPACE prize (Sanofi-Synthelabo Prize for Assessing Costs in Epilpesy), sponsored by the International Bureau for Epilepsy and SanofiSynthelabo. The psychosocial research programme at the A and RMC is supported by ongoing funding from GlaxoWellcome, $\mathrm{RMC}$ is supported by ongoing funding from GlaxoWellcome,
Australia. We express our gratitude to Professor Sam Berkovic, Australia. We express our gratitude to Professor Sam Berkovic,
Director of the Comprehensive Epilepsy Programme, for his invaluable support.

1 Horsley V. Brain surgery. BMF 1886;ii:670-5.

2 MacEwen W. Tumour of the dura mater removed during life in a person a

3 Morris AA. The surgical treatment of psychomotor epilepsy. Medical Annals of District of Columbia 1950;19:123-31.

4 Bailey P, Gibbs FA. The surgical treatment of psychomotor epilepsy. IAMA 1951;145:365-70.

5 Penfield W, Flanigin H. Surgical therapy of temporal lobe Penfield W, Flanigin H. Surgical therapy of temp

6 Green JR, Duisberg REH, McGrath WB. Focal epilepsy of psychomotor type. a preliminary report of observations and psychomotor type. a preliminary report of observations

7 Falconer MA, Hill D, Meyer A, et al. Treatment of temporal lobe epilepsy by temporal lobectomy: a survey of findings and results. Lancet $1955 ; \mathrm{i}: 827-35$.

8 Hill D, Pond DA, Mitchell W, et al. Personality changes following temporal lobectomy for epilpesy. f Ment $\mathrm{Sc}$ 1957;103:18-27.

9 Simmel ML, Counts S. Clinical and psychological results of anterior temporal lobectomy in patients with psychomotor epilepsy. In: Baldwin M, Bailey P, eds. Temporal lobe epilepsy:

a colloquium. Illinois: Thomas Springfield, 1958:530-50. fournal of Mental Science 1960;106:213-8.

11 Falconer MA, Serafetinides EA. A follow-up study of surgery in temporal lobe epilepsy. $f$ Neurol Neurosurg Psychiatry 1963:26;154-65.

12 Taylor DC, Falconer MA. Clinical, socio-economic, and psychological changes after temporal lobectomy for epipsychological changes after temporal lo
lepsy. Br $\mathcal{A}$ Psychiatry 1968;114:1247-61.

13 Horowitz MJ, Cohen FM. Temporal lobe epilepsy: effect of lobectomy on psychosocial functioning. Epilepsia 1968;9 $23-41$.

14 Ferguson SM, Rayport M. The adjustment to living withou epilepsy. F Nerv Ment Dis 1965;140:26-37.

15 von Senden M. Space and sight: the perception of space and shape in the congenitally blind before and after operation. Illinois: Free Press, 1960:99-103; 156-69.

16 Wishengrad $M$. The rope dancers. New York: Crown, 1958.

17 Kaplan SM. Psychological aspects of cardiac disease: a study of patients experiencing mitral commissurotomy. Psychosom Med 1956;18:221-33.

18 Penman J. Pain as an old friend. Lancet 1954;i:633-6.

19 Bladin PF. Medical and social prognosis of temporal lobectomy. In: Vajda FJE, Berkovic SF, Donnan GA, eds. Epilepsy update: proceedings of a workshop at the Austin HospiEpilepsy update: proceedings of a workshop at the Austin Hospi-

20 Bladin PF. Psychosocial difficulties and outcome after temporal lobectomy. Epilepsia 1992;33:898-907.

21 Bladin PF. Social outcome after seizure surgery in Australia [abstract]. Epilepsia 1993;34(suppl 2):180

22 Horowitz MJ, Cohen FM, Skolnikoff AZ, et al. Psychomotor epilepsy: rehabilitation after surgical treatment. $\mathcal{F}$ Nerv Ment Dis 1970;150:273-90.

23 Jensen I. Temporal lobe epilepsy: social conditions and rehabilitation after surgery. Acta Neurol Scand 1976;54:22 44.

24 Rausch R, Crandall PH. Psychological status related to surgical control of temporal lobe seizures. Epilepsia 1982;23 191-202.

25 Guldvog B, Løyning Y, Hauglie-Hanssen E, et al. Surgical versus medical treatment for epilepsy. II. Outcome related to social areas. Epilepsia 1991;32:477-86.

26 Fraser RT, Thorbecke R. Postoperative rehabilitation. In: Engel J Jr, Pedley TA, eds. Epilepsy: a comprehensive Engel J Jr, Pedley TA, eds. Epilepsy: a comprehensive

27 Wilson SJ, Kincade P, Saling MM, et al. Patient readmission and support utilisation post-anterior temporal lobectomy.

28 McCullough MA, Day S, Herlihy E, et al. Using a multidisciplinary follow up program to assist patient adjustment following temporal lobectomy. F Neurosci Nurs 1989;21: 295-304

29 Taylor DC, Neville BGR, Cross JH. New measures of outcome needed for the surgical treatment of epilepsy. Epilepsia 1997;38:625-30.

30 Vickrey BG, Hays RD, Hermann BP, et al. Outcomes with respect to quality of life. In: Engel J Jr, ed. Surgical treatment of the epilepsies. 2nd ed. New York: Raven Press, 1993:62335 .

31 Benbadis SR, Chelune GJ, Stanford LD, et al. Outcome and complications of epilepsy surgery. In Wyllie E, ed. The treatment of epilepsy: principles and practice. 2nd ed. treatment of epilepsy: principles and practice.
Baltimore: Williams and Wilkins, 1996:1103-18.

32 Devinsky O, Baker G, Cramer J. Quantitative measures of assessment. In: Engel J Jr, Pedley TA, eds. Epilepsy: a comprehensive textbook. Philadelphia: Lippincott-Raven, 1997: prehensive
33 Vickrey BG, Hays RD, Graber J, et al. A health-related quality of life instrument for patients evaluated for epilepsy surgery. Med Care 1992:30:299-319.

34 Baker GA, Camfield C, Camfield P, et al. Commission on outcome measurement in epilepsy, 1994-7: final report. Epilepsia 1998;39:213-31.

35 Vickrey BG, Hays RD, Rausch R, et al. Outcomes in 248 patients who had diagnositc evaluations for epilepsy surgery. Lancet 1995;346:1445-9.

36 Gilliam F, Kuzniecky R, Meador K, et al. Patient-oriented outcome assessment after temporal lobectomy for refractory epilepsy. Neurology 1999;53:687-94.

37 Wiebe S, Rose K, Derry P, et al. Outcome assessment in epilepsy: comparative responsiveness of quality of life and psychosocial instruments. Epilepsia 1997;38:430-8

38 McLachlan RS, Rose KJ, Derry PA, et al. Health-related quality of life and seizure control in temporal lobe epilepsy. Ann Neurol 1997;41:482-9.

39 Rose KJ, Derry PA, Wiebe S, et al. Determinants of healthrelated quality of life after temporal lobe epilepsy surgery. Qual Life Res 1996;5:395-402.

40 O'Donoghue MF, Duncan JS, Sander JWAS. The subjective handicap of epilepsy: a new approach to measuring treatment outcome. Brain 1998;121:31-43

41 Spencer SS, Hunt PW. Quality of life in epilepsy. F Epilepsy 1996;9:3-13.

42 Headey B, Wearing A. Understanding happiness: a theory of subjective well-being. Melbourne: Longman Chesire, 1992.

43 Cummins RA, Baxter C. Subjective quality of life is maintained under homeostatic control: implications for measurement. Proceedings, of the 2nd International Conference on Quality of Life in Cities. Singapore: National University of Singapore, 2000 (in press).

44 Cummins RA. Assessing quality of life. In: Brown RI, ed. Quality of life for people with disabilities: models, research and practice. 2nd ed. Cheltenham: Stanley Thornes, 1997:116-

45 Bradburn NM. The structure of psychological well-being. Chicago: Aldine, 1969.

46 Headey BW, Holmstrom EL, Wearing AJ. Well-being and ill-being: different dimensions? Social Indicators Research 1984;14:115-39.

47 Watson D, Clark LA, Tellegen A. Development and validation of brief measures of positive and negative affect: the PANAS scales. F Pers Soc Psychol 1988;54:1063-70.

48 Watson D. The vicissitudes of mood measurement. $\mathcal{F}$ Pers Soc Psychol 1988;66:128-41.

49 Wilson SJ, Saling MM, Kincade P, et al. Patient expectations of temporal lobe surgery. Epilepsia 1998;39:167-74

50 Wilson SJ, Saling MS, Lawrence J, et al. Outcome of temporal lobectomy: expectations and the prediction of perceived success. Epilepsy Res 1999;36:1-14.

51 Bladin PF, Wilson SJ, Saling MM, et al. Outcome assessment in seizure surgery: the role of post-operative adjustment. $\mathcal{F}$ Clin Neurosci 1999;6:313-8.

52 Burckhardt CS. Coping strategies of the chronically ill. Nurs Clin North Am 1987;22:543-9.

53 Taylor DC. Epilepsy as a chronic sickness: remediating its mpact. In: Engel J Jr, ed. Surgical treatment of the epilepsies. 2nd ed. New York: Raven Press, 1993:11-22.

54 Ryan R, Kempner K, Emlen AC. The stigma of epilepsy as a self-concept. Epilepsia 1980;21:433-44.

55 Bagley C. Social prejudice and the adjustment of people with epilepsy. Epilepsia 1972;13:33-45

56 Tedman S, Thornton E, Baker G. Development of a scale to measure core beliefs and perceived self efficacy in adults with epilepsy. Seizure 1995;4:221-31.

57 Wheelock I, Peterson C, Buchtel HA. Presurgery expectations, postsurgery satisfaction, and psychosocial adjustment after epilepsy surgery. Epilepsia 1998;39:487-94

58 Blumer D, Walker AE. Sexual behaviour in temporal lobe epilepsy. Arch Neurol 1967;16:37-43.

59 Engel J, Caldecott-Hazard S, Bandler R. Neurobiology of behaviour: anatomic and physiological implications related to epilepsy. Epilepsia 1986;27(suppl 2):S3-13.

60 Chovaz CC, McLachlan RS, Derry PA, et al. Psychosocial function following temporal lobectomy: influence of seizure control and learned helplessness. Seizure 1994;3:171-6.

61 Blumer D, Wakhlu S, Davies K, et al. Psychiatric outcome of temporal lobectomy for epilepsy: incidence and treatment of psychiatric complications. Epilepsia 1998;39:478-86.

62 Ring HA, Moriarty J, Trimble MR. A prospective study of the early postsurgical psychiatric associations of epilepsy surgery. $\mathcal{F}$ Neurol Neurosurg Psychiatry 1998;64:601-4.

63 O'Shea MF, Saling MM, Bladin PF, et al. Does naming contribute to memory self-report in temporal lobe epilepsy? f Clin Exp Neuropsychol 1996;18:98-109.

64 O'Shea MF. The cognitive and affective correlates of the memory complaint in temporal lobe epilepsy [doctoral dissertation]. Melbourne, Australia: University of Melbourne, 1996.

65 Derry PA, Rose KJ, McLachlan RS. Moderators of the effect of pre-operative emotional adjustment on postoperative depression after surgery for temporal lobe epilepsy. Epilepsia 2000;41:177-85.

66 Carran MA, Kohler CG, O'Connor MJ, et al. Marital status after epilepsy surgery. Epilepsia 2000;40:1755-60.

67 Derry PA, Chovaz CJ, McLachlan RS, et al. Learned resourcefulness and psychosocial adjustment following temporal lobectomy in epilepsy. F Soc Clin Psychol 1993;12: 454-70. 